\title{
Research on Intelligent City Oriented to residents' public service demand
}

\author{
Ruan Mingyang \\ Kunming University, Kunming 650214, China
}

\begin{abstract}
Keywords: Intelligent city; public service; residents' needs; Internet of things; cloud platform
\end{abstract}

\begin{abstract}
Intelligent city uses the current advanced communication and network technology to make intelligent response to the core management system of urban operation, so as to meet the needs of residents' public services. For the public service needs of residents, the residents of the intelligent city, the demand for public services are discussed, and the analysis of the overall solution of public service platform for the intelligent city, and put forward the key technology of intelligent city and strategies for public service needs of residents. Using advanced technologies such as Internet of things and cloud platform can realize intelligent management and operation of the city, and create a better life for the people in the city, and promote the harmonious and sustainable growth of the city.
\end{abstract}

\section{Introduction}

Due to the rapid development of China's economy, the speed of urban development is advancing by leaps and bounds, our city urbanization rate has exceeded $50 \%$, while the rate of city to promote economic development and social progress, but also brought a series of problems of shortage of resources and environmental pollution, traffic jams and so on, in order to solve this problem, need to establish the new city development model, in order to ensure the sustainable prosperity of the city. In order to rapidly develop a series of achievements and city make the new technology revolution brought the combination, but also to follow the objective law of development of the city, brought to effectively solve the problems in the development of the city, has become the inevitable choice of wisdom city.

\section{Intelligent city residents' demand for public services}

In the process of intelligent city construction, the public service needs of residents include various fields and aspects, such as life direction, transportation and education, etc., the following are introduced.

Demand for life. In life, the intelligent city residents demand for public services mainly include the costs of various queries, such as water query and electricity query, using WAP, WEB, client, city residents can utilities through the wireless city convenient to check the latest, water can be provided by the tap water company, electricity can be supplied by power supply the data provided by the Bureau, including the use of hydropower and historical bills in real time, so that residents living more convenient.

Demand for Traffic. Traffic is an important aspect of public service needs of residents, the use of WAP, WEB, client, intelligent city for motor vehicle and non motor vehicle drivers and pedestrians for violation of traffic safety or traffic management method of some real-time and historical data query, real-time integration to help drivers, for motor vehicles non motor vehicle 
drivers and pedestrians to provide real-time traffic and video, and the map query and other functions.

Demand for Education. For the educational demand, intelligent city can provide residents with public services including mobile phone library, exam results and the examinee information query, the use of mobile phone library can be extended to the public library service function of wireless city platform, which can provide greater convenience for the residents of education.

\section{Intelligent city public service platform as a whole solution}

Intelligent city public service platform according to the different needs of the residents service demand, the demand in different fields of data integration, to provide a public service platform and public service platform to respond according to the real-time demand information, the overall framework is shown in Figure 1.

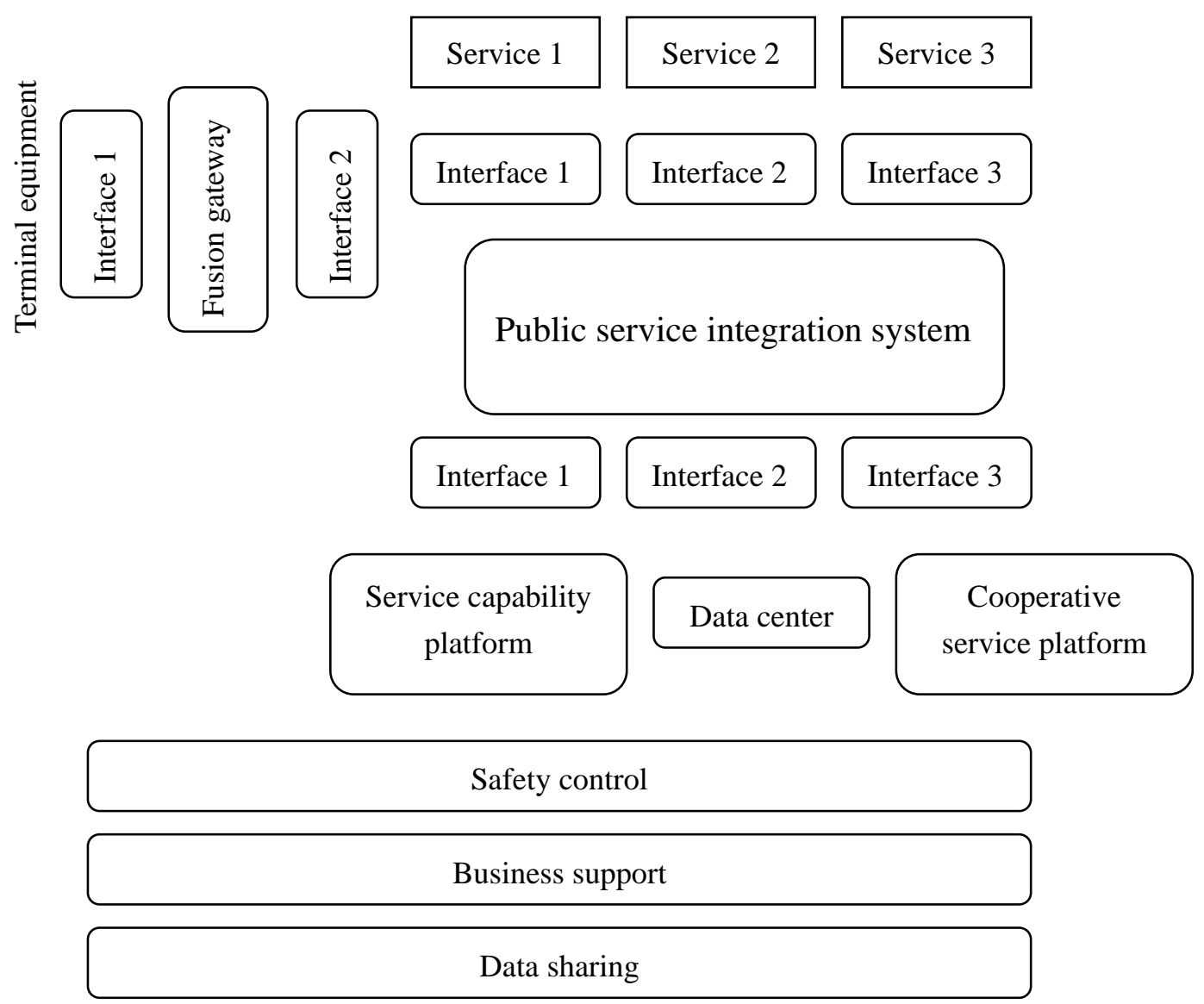

Figure 1 Intelligent city public service integration system

As shown in Figure 1, the wisdom of the city public service system integration platform is mainly composed of six functional modules, including terminal equipment, fusion gateway, service integration system, service capability platform, data center and public service platform.

(1) Terminal equipment

The terminal device is the main tool of event triggering, and the public service can be provided by the trigger

Send to the fusion gateway, send the service request to the public service integration system through the docking of the data interface.

(2) Fusion gateway 
The fusion gateway mainly converts the request information sent by the terminal equipment into a unified format, that is, the format of the service integration system open to the outside world, and realizes the call of the terminal information.

(3) Service integration system

This part is the core part of the service platform, the various hardware and software resources package, and according to certain standard and normative constraints on language, effective communication can realize all kinds of services, to maximize the realization of the compatibility of the system, so as to improve the service system of portability and scalability.

(4) Service capability platform

Service platform mainly is the use of telecommunications operators, to provide technical support for the integrated service system, such as SMS, WAP, Java, GIS, streaming media and digital tools series, with operator service capabilities, more services will be introduced to the platform.

(5) Data center

As the service platform of the data center can be a variety of services to save data, including a variety of terminal information, service information, system response information, because of the large amount of data, often need the help of cloud computing platform.

(6) Public service platform

The wisdom of the city's public service platform can rely on the maintenance and management of the government or non-profit organizations to provide various services for the residents demand, is also the focus of the whole service system part.

\section{Key technology and strategy of intelligent city oriented to residents' public service demand}

In order to ensure the normal operation of the service system for intelligent city public service needs of residents, with some high-end technology of existing and newly developed some typical wisdom city management system, such as networking, cloud platform and wisdom education management system etc..

(1) Internet of things technology

Intelligent city, as an organic large system, covers all aspects of residents' public service needs

This requires a super network with terminal interconnection and intelligent service, and the Internet of things can meet this demand, and has become a very important element of intelligent city. Networking technology can not only provide the city's perception to the wisdom of the city, such as environmental perception, perception of lighting and traffic conditions can provide perception, perception of the health status of residents and living conditions, provides great convenience for the intelligent management of municipal, livelihood and other aspects of the industry.

(2) Cloud platform

The cloud platform is a resource sharing service based on network technology, the use of cloud platform can realize resource allocation according to need, so as to promote the effective use of resources, intelligent city service integration system is a complex system with multiple areas of integration, interaction between the various fields of resources and sharing of information, which is suitable for the system architecture using cloud computing platform, cloud computing platform can achieve massive data processing, the public service system is to solve the data processing problem of a good strategy.

(3) City intelligent public traffic management system

Intelligent city traffic system by dynamic electronic stop sign, display real-time vehicle information, and electronic bus stop and free wireless network, can obtain the vehicle travel routes and transfer information through the use of mobile phone browsing mode of electronic bus stop. At 
the same time, the traffic management part can also obtain the road blocking condition in real time through the intelligent traffic management system, so as to rationally allocate the bus route and departure scheduling time, and realize the intelligent management of the bus.

(4) Intelligent pedagogy card program

With the digital and information construction of the campus gradually, all kinds of information resources integration in the campus has entered the planning and implementation stages, intelligent card has the function of student information storage and RFID RF induction type data exchange between the reader and card equipment, thus realizing the books borrowing, selection and other functions, and also card for teachers, students and parents to provide a platform for the exchange of information with wisdom, so as to provide an information, for the wisdom of educational intelligent learning environment, creating a new era of home school internet.

\section{Conclusion}

For the public service needs of residents, this study proposes a public service platform for smart city solutions and related key technologies and strategies, and taking needs of the residents in daily life, transportation and education as an example, to construct the service system of the wisdom of the city to carry out in-depth analysis and discussion, summarizes a series of plans and Strategies of wisdom the construction of the city. The wisdom of the city can be combined with the new technology of the industrial revolution, the objective law of development of the city and the combination of promoting the harmonious development of the city, for the study of the development of modern city, has the important practical significance.

\section{Acknowledgements}

The work was supported by the construction project of Yunnan society, frontier and ecological environment research from Innovation team of philosophy and Social Sciences in Yunnan.

\section{Reference}

[1] Wang Jianqiang, Wu Chenwen, Li Xiaojun. Research on vehicle networking architecture and key technologies [J]. Microcomputer Information, No. 04, (2011) , p.156-158

[2] Tang Xiaolin, Lin Peiqun, Xu Jianmin. Research on car networking architecture and key technology based on Cloud computing and WSN [J]. Journal of Transport Iinformation and Safety, No.05, (2011), p.106-111

[3] Nie Yanmin, Wu Hongle, Chen Gang. Research on smart city architecture supported by big data [J]. Wireless internet Technology, No.9, (2016).

[4] Qin Xiao, Zhen Feng, Xiong Lifang, Zhu Shoujia. Research methods of urban space behavior in big data era [J]. Progress in Geograghy, No.9, (2013).

[5] Zou Guowei, Cheng Jianbo. The application of big data technology in intelligent city [J]. Telecommunications Network Technology, No.4, (2013).

[6] Chai Yancheng, Shen Yue, etc.. The application of big data in China's intelligent city planning to explore the $[\mathrm{J}]$. Urban Planning International, No.6, (2014).

[7] Lu Keyuan. On the application of big data in the research and planning of intelligent city [J]. Housing and Real Estate, Vol.27, (2016). 
[9] He Yao, Wang Wenqing, Xue Fei. Research on massive data mining based on cloud computing [J]. Computer Technology and Development, Vol.23(2) , (2013), p.69-72

[10] Ding Yan, Yang Qingping, Qian Yuming. Platform architecture and its key technology research of [J]. ZTE Technology Journal, Vol.19 (1), (2013), p.53-60

[11] Xu Xiongwei, Wang Ping, Xu Shiwu. Research and discussion of wireless sensor network synchronization algorithm [J]. Microcontroller \& Embedded systems, Vol.12(3), (2012), p.8-11.

[12] Si Haifei, Yang Zhong, Wang Jun. Wireless sensor network research situation and application of [J]. Journal of Mechanical \& Electrical Engineering, Vol.28 (1), (2011), p.16-20.

[13] Cui Suhui, Chen Guangting, Li Ruxue. Repeater placement in three dimensional wireless sensor networks [J]. Journal of Hangzhou Dianzi University, Vol.30 (2), (2010), p.81-84.

[14] Zhao Yafei. Application of big data and smart city research and planning [J]. Shanxi Architecture, Vol.23, (2016).

[15] Wu Lanlan. Research on planning method and innovation of intelligent city [J]. Science \& Technology Information, No.05, (2013) 